pp. $25 \mathrm{I}$ ff., May, I92I) and, with theory and methods used, in the Philippine Journal of Science (vol. I7, pp. $607-14,1920$ ).

The time observations, made with field-glass or telescope, stop-watch, and ordinary watch, show that with type A there is, on the whole, a slight excess of observed duration over computed, amounting for forty-four cases to 0.55 per cent.; a few cases give small deficiencies. This may be, perhaps, explained by atmospheric dispersion. Type B, however, always gives excess, sometimes remarkably large, even 2 min., or 68 per cent., with an average excess for twenty-two cases of 12.3 per cent., which is difficult to explain.

Records of duration of sunrise and sunset are almost non-existent; a careful search, with inquiries of several prominent astronomers, has failed to produce more than about half a dozen, mostly made by Le Gentil at Pondichéry in 1769 while on his transit of Venus expedition. While he made no such use of them, on computing they give results in agreement with the above. It would seem, perhaps, worth while for others to take the matter up and record and publish at least date and hour, geographical position, nature of horizon, duration, and type or form of disc. The horizon should be quite level or distant if at all irregular. Naturally, the best horizon is that of the sea or a large lake; but I have reason to believe that the results of observing with a distant level land horizon might be sometimes quite extraordinary.

While the sun is the source of light in such observations, and the Nautical Almanac and four-place logarithms have to be used in the computing, the subject is not astronomical, but meteorological, and, I believe, has to do with temperature distribution in the atmosphere. We have here one of those residual phenomena the study of which may lead to the discovery of interesting facts and which can be forwarded by amateur observers, the more and the more widely scattered the better.

Cambridge, Mass., September I4.

Willard J. Fisher.

\section{Is Bisexuality in Animals a Function of Motion?}

IN NATURE of September 29, p. 145, Dr. Orton makes the interesting suggestion that bisexuality in animals may be causally connected with the development of a freely moving, as opposed to the sessile or sluggish, habit. Reviewing the incidence of hermaphroditism and bisexuality in the animal kingdom, he reasserts the proposition put forward by Claus that hermaphroditism is found most frequently in fixed, parasitic, and sluggish animals. The two modes of reproduction may therefore be functions of the degree of motor activity manifested by animals.

I do not wish to contradict Dr. Orton's general proposition, especially as he has framed it tentatively and without dogma. But I would like to point out that in the Mollusca we have an excellent opportunity of testing the truth of the suggestion in a single group. The streptoneurous Gastropoda are, with some exceptions, bisexual; the Euthyneura are exclusively hermaphrodite. I do not think, however, that we can select the Euthyneura as exclusively "sluggish" animals and the Streptoneura as exclusively "active." The Pulmonata' (Euthyneura), with their lengthy æstivation or hibernation period, might be regarded as more sluggish than the average Prosobranch. But other Euthyneura which apparently do not æstivate or hibernate for a long period cannot be regarded as more sluggish than the Streptoneura,

NO. 27 I I, VOL. IO8] viz. the Tectibranchs and Nudibranchs. Having kept many of these animals in captivity myself, I can testify that they are no less active than Streptoneura observed under similar conditions. An Aplysia is not more sluggish than a Buccinum or a Paludestrina. I admit that an intimate study of the habits of all Gastro. poda is not available, but the known facts go to show that many of the hermaphrodite forms are as active as the bisexual ones. Dr. Orton may reply that many of the apparently bisexual forms may be liable to intermittent hermaphroditism. I have no doubt that permanent and intermittent hermaphroditism may be commoner in the Streptoneura than we imagine, but all the evidence accumulated over many years goes to show that bisexuality is regular and very widely developed among this group. During the last two years, for example, I have examined more than a hundred examples of various species of Paludestrina and kindred genera, and not found a single hermaphrodite form. In Pelseneers's "Variations et leur Hérédité chez les Mollusques" (I920) there are only five genera cited in which occasional hermaphroditism is recorded, though doubtless Dr. Orton could add a few more to the list.

The suggestion that hermaphroditism is either the direct result of the sedentary habit or that it is in some way facultative for animals leading such a mode of life is indeed interesting. But in that case it is difficult to see why it is not found as the exclusive mode of reproduction among the Scaphopoda, the Lamellibranchia, and the Polyplacophora (Chitons), which are all, on the whole, more sluggish than the Streptoneura. Dr. Orton's proposition may well be true of sessile or parasitic forms, but it scarcely seems to be true of animals which are merely sluggish. It should be pointed out that great diversity of habit occurs in the various groups of Gastropoda which might on a superficial view, perhaps, be categorised as "active" or "sluggish." Along with really sluggish forms are associated species which are active swimmers, burrowers, and climbers. Finally, it might be asked whether the locomotor test is an entirely safe criterion of physiological "sluggishness" or "activity."

Zoological Department, British Museum

(Natural History), October 3 .

\section{An Algebraical Identity.}

IN NATURE of July 2 I (vol. ro7, p. 652) appears a letter from Mr. W. E. H. Berwick, inquiring whether the values of $y, z$ satisfying the equation $z^{2}-p y^{2}=-4$, which are derivable from Gauss's cyclotomic formulæ, constitute generally the primitive solution of this equation. In reply I have to point out that a comparison of Gauss's formulæ (Mathews, "Theory of Numbers," p. $21_{5}$ ) with Kronecker's formula

$$
\left\{\frac{1}{2}(\mathrm{~T}+\mathrm{U} \sqrt{\mathrm{D}})\right\}^{h}=\Pi\left(\mathrm{I}-\omega^{g^{2 n+1}}\right) / \Pi\left(\mathrm{I}-\omega^{\theta^{2 n}}\right)
$$

(Mathews, p. 253), where $\mathrm{T}^{2}-\mathrm{DU}^{2}=4$ is the primitive solution of this equation, $T$ and $U$ being positive, shows that $z, y$ are connected with the primitive solution $a, b$ by the relation

$$
\frac{|z|+\sqrt{ } p|y|}{2}=\left(\frac{a+\sqrt{ } p b}{2}\right)^{h}
$$

where $h$ is the number of properly primitive classes of determinant $p$. Incidentally, ic appears that $\%$ is always positive and $v$ negative.

September 20 .
R. F. Whitehead. 